\title{
LiDAR Applications to Estimate Forest Biomass at Individual Tree Scale: Opportunities, Challenges and Future Perspectives
}

\author{
Dandan $\mathrm{Xu}{ }^{1}{ }^{1}$, Haobin Wang ${ }^{1}$, Weixin $\mathrm{Xu}^{2}{ }^{2}$, Zhaoqing Luan ${ }^{1}$ and $\mathrm{Xia} \mathrm{Xu}{ }^{1, *}$ \\ 1 Department of Ecology, College of Biology and the Environment, Nanjing Forestry University, \\ Nanjing 210037, China; dandan.xu@njfu.edu.cn (D.X.); wanghaobin@njfu.edu.cn (H.W.); \\ luanzhaoqing@njfu.edu.cn (Z.L.) \\ 2 College of Resource and Environment, Chengdu University of Information and Technology, \\ Chengdu 610103, China; weixin.xu@cuit.edu.cn \\ * Correspondence: xuxia.1982@njfu.edu.cn
}

check for updates

Citation: $\mathrm{Xu}, \mathrm{D}$.; Wang, H.; Xu, W.; Luan, Z.; Xu, X. LiDAR Applications to Estimate Forest Biomass at Individual Tree Scale: Opportunities, Challenges and Future Perspectives. Forests 2021, 12, 550. https://doi.org/ $10.3390 /$ f12050550

Academic Editor: John Couture

Received: 12 March 2021

Accepted: 26 April 2021

Published: 28 April 2021

Publisher's Note: MDPI stays neutral with regard to jurisdictional claims in published maps and institutional affiliations.

Copyright: (c) 2021 by the authors. Licensee MDPI, Basel, Switzerland. This article is an open access article distributed under the terms and conditions of the Creative Commons Attribution (CC BY) license (https:// creativecommons.org/licenses/by/ $4.0 /)$.

\begin{abstract}
Accurate forest biomass estimation at the individual tree scale is the foundation of timber industry and forest management. It plays an important role in explaining ecological issues and small-scale processes. Remotely sensed images, across a range of spatial and temporal resolutions, with their advantages of non-destructive monitoring, are widely applied in forest biomass monitoring at global, ecoregion or community scales. However, the development of remote sensing applications for forest biomass at the individual tree scale has been relatively slow due to the constraints of spatial resolution and evaluation accuracy of remotely sensed data. With the improvements in platforms and spatial resolutions, as well as the development of remote sensing techniques, the potential for forest biomass estimation at the single tree level has been demonstrated. However, a comprehensive review of remote sensing of forest biomass scaled at individual trees has not been done. This review highlights the theoretical bases, challenges and future perspectives for Light Detection and Ranging (LiDAR) applications of individual trees scaled to whole forests. We summarize research on estimating individual tree volume and aboveground biomass (AGB) using Terrestrial Laser Scanning (TLS), Airborne Laser Scanning (ALS), Unmanned Aerial Vehicle Laser Scanning (UAV-LS) and Mobile Laser Scanning (MLS, including Vehicle-borne Laser Scanning (VLS) and Backpack Laser Scanning (BLS)) data.
\end{abstract}

Keywords: forest aboveground biomass; LiDAR; individual tree scale; UAV-LS; Backpack Laser Scanning

\section{Introduction}

Accurate forest biomass estimation is the foundation of timber industry (timber, fiber and bioenergy) and forest management (forest plantation and natural resources). It is the key to ecological research and the basis for a range of fields including forest productivity, energy flux, carbon and nitrogen cycling, nutrient cycling and forest dynamics. Additionally, it is a critical biophysical parameter to describe the characteristics of forest ecosystems [1-4]. In the past, the focus of forest biomass estimation has been on timber quality and quantity [5], but this has shifted to forest carbon sequestration under the impetus of global climate change [6]. Studies of forest biomass play an important role in monitoring forest carbon sequestration and the role of forest function on regional and global carbon flux [7-9].

One way to measure carbon storage in forest ecosystems is to calculate the product of forest biomass and carbon content [10]. Therefore, it is important to accurately and rapidly monitor forest biomass to understand the impact of climate change on forest carbon sinks and implement policies to mitigate the influences of climate change on forest ecosystems [11-13]. 
Estimating forest biomass at the individual tree scale can advance accurate forest biomass investigation. Perhaps more importantly, evaluating forest biomass and dynamics at the individual tree scale is the foundation of understanding specific ecological process (e.g., the impact of environment factors on tree growth, competition between individual trees, etc.). The challenge is to replicate forest biomass estimation at population, community, ecoregion and global scales.

Monitoring forest biomass at the individual tree scale has two strengths: (1) summing growth responses of individual trees can follow species shifts at multiple ecological scales [2], and (2) forest biomass estimation at the individual tree scale could reduce the bias arising from spatial and temporal heterogeneity [14], including species-specific forest biomass estimation [15], habitat-specific forest biomass estimation [16] and managementspecific forest biomass estimation [17]. Both environmental factors and forest management polices influence variation among individual trees in the forest ecosystem [7] and global climate change is predicted to further affect the metabolism of individual trees [18,19]. This will ultimately impact forest ecosystem heterogeneity. Forest biomass growth rate at the individual tree scale is an indicator of ecological response to a variety of ecological process, including ontogeny, intensity of individual competition, impact of environment factors on individual tree growth and succession [20-22]. Therefore, research in the field of forest biomass estimation would benefit from a focus on individual tree processes.

Remotely sensed images, with variable spatial and temporal resolution, with their advantage of non-destructive monitoring, are widely applied in forest research, especially following the first Landsat satellite launch [23]. Comparing methods of measuring forest biomass in the field (i.e., destructive sampling and allometric equations based on Diameter at Breast Height (DBH) and tree height), remote sensing techniques have two non-fungible advantages: continuous monitoring of forest biomass dynamics [24,25] and forest biomass heterogeneity mapping [26]. Remote sensing techniques have been widely studied as a forest biomass estimator since the first Landsat satellite was launched in 1972. Intuitively, optical remote sensing imagery (e.g., AVHRR, Landsat, MODIS and SPOT) should have advantages over ground-based methods to monitor temporal dynamics of forest biomass [25-31]. Most commonly, optical remote sensing focuses on tree biomass estimation at the global, ecoregion or community scale. In contrast, ecological research emphasizes tree biomass sampling at the individual and population scale, and then generalizes to forest biomass at community, ecosystem, ecoregion and global scales. However, the low accuracy of optical satellite imagery with moderate or low spatial resolution has inhibited advances in forest vegetation population or vegetation community prediction. Due to spatial resolution constraints with and evaluation accuracy of remotely sensed data, the development of remote sensing estimation of forest biomass at the individual tree and population scales has been relatively slow [32] compared to that at global, ecoregion and vegetation community scales. With improvements in platform spatial and spectral resolution (e.g., QuickBird and Worldview2), along with the continual development of remote sensing techniques, the potential to identify single tree crown boundaries [13] and tree species [33] has been demonstrated. Nevertheless, optical remotely sensed data has failed to consistently estimate forest biomass because it has not been possible to image three-dimensional (3D) forest structure. Light Detection and Ranging (LiDAR) data has changed this with its potential to precisely measure forest biomass at the plot, forest stand or regional scale [34].

Therefore, it represents a significant advance for forest biomass estimation to promote LiDAR applications at the individual tree scale for its potential contributions to concepts and techniques in ecological remote sensing. Nevertheless, a comprehensive review of LiDAR applications for forest biomass at the individual tree scale has not been done. This review will fill that gap by summarizing the literature of forest biomass estimation at the individual tree scale using LiDAR operated from four platforms: terrestrial laser, airborne, Unmanned Aerial Vehicle (UAV) and mobile laser (i.e., vehicle or backpack). This review will discuss the theoretical bases and challenges of LiDAR application in forest 
aboveground biomass (AGB) estimation at the individual tree scale, and identify future perspectives for forest biomass estimation of individual trees using LiDAR data.

\section{Current Methodology and Challenges for Forest Biomass Estimation at the Individual Tree Scale}

\subsection{Allometric Equation (Traditional Forest Estimation at the Individual Tree Scale)}

Direct measurement of forest biomass is based on time-consuming, destructive methods. Increasingly, to mitigate the drawbacks of such sampling, studies have focused on models to estimate forest biomass in tropical, temperate and boreal ecosystems. The national forest inventory of China also proposed to monitor forest biomass at the individual tree scale in 2009 [10]. Forest biomass models built at the individual tree scale are largely allometric equations based on DBH [35] or both DBH and tree height [36]. Some allometric equations also include the ratio of tree height and $\mathrm{DBH}$, crown diameter, crown height and basal area $[1,3]$. Because the relationship between biomass, DBH and tree height varies among tree species, and affects statistical indicators of optimum biomass selection $[16,37,38]$, the forest biomass model developed for one region may not globally apply to other regions or ecosystems. Hofstand's [1] research indicates that the accuracy of a DBH-based allometric model exceeds $95 \%$ in arid regions and tree height does not contribute to tree biomass estimation. However, Zeng et al.'s [36] research suggests that the allometric equation developed using both tree height and DBH is superior to that using DBH only for Chinese pine (Pinus tabulaeformis Carr.). Ter-Mikaelian and Korzukhin [39] reviewed 803 forest biomass models for 65 tree species in North America, and the summarized results show that allometric model parameters are significantly different even though they are all built based on DBH only. Oliveira et al.'s [15] research indicates that allometric algorithms vary among gene types of the same tree species. In conclusion, these allometric equations are often region-specific (i.e., equations built in one region are not applicable for other regions, vegetation community or ecoregions), due to different tree species, environmental factors, management policies, stand density and age.

To develop forest biomass models at the individual tree scale with high accuracy and wide application, researchers have made significant modifications to forest stand-specific and species-specific forest biomass models by adding tree species as dummy variables into allometric equations and enlarging samples to reduce the impact of heterogeneity within and among forest ecosystems. Dong et al. [40] separated the allometric equation for forest biomass estimation for conifer and hardwood mixed forest, conifer mixed forest and khingan fir forest in boreal forest regions of China. Tahvanainen and Forss [41] also established forest biomass models for individual Scots pine (Pinus sylvestris), Norway spruce (Picea abies), downy birch (Betula pubescens) and silver birch (B. pendula) in Finland. Some studies have considered tree species as dummy input variables for forest biomass models to reduce the influence of species on biomass model accuracy [42,43]. Fu et al. [43] enlarged the sample size in all types of forest ecosystems in China to integrate heterogeneity effects into allometric equations for forest biomass estimation. Some research has concluded that, even for the same tree species, the relationship between DBH and height varies significantly among locations [14]. Stand age [44], stand density [15], environment [3], forest management [17] and the difference between plantation and natural forest [42] have the potential to cause significant differences in allometric biomass algorithms. However, few studies have focused on the influence of those factors on allometric biomass equations. Therefore, a fruitful future direction may be to analyze the habitat- and managementspecific allometric algorithms for forest biomass at the individual tree scale.

\subsection{Applying LiDAR for Forest Biomass Estimation at the Individual Tree Scale}

Unlike forest stand biomass estimation, forest biomass and tree size are strongly related at the individual tree scale $[45,46]$. LiDAR remote sensing has been shown to be able to measure forest biophysical parameters automatically with high accuracy [47]. This has been especially useful to capture forest vertical structure [48], an estimate of 
tree size that is closely related to tree biomass [49]. In the literature, LiDAR remote sensing precisely measured tree size and structure parameters including height, crown boundary, stand density, crown projected area, tree bounding volume, basal area and canopy height [5,6,8,50-52]. LiDAR systems include full-waveform recording and discrete returns [48]. Full-waveform LiDAR digitizes the entire reflected amplitude from a return to measure a complete vertical vegetation profile compared to discrete-return LiDAR that records single or multiple returns from a given laser pulse to form point clouds representing intercepted forest vertical features [48,53]. LiDAR remote sensing is usually classified by the five primary platform types: Terrestrial Laser Scanning (TLS), Airborne Laser Scanning (ALS), Unmanned Aerial Vehicle Laser Scanning (UAV-LS), Mobile Laser Scanning (MLS, Simultaneous Localization and Mapping (SLAM) or Portable Canopy LiDAR (PCL) carried by a backpack or vehicle) and Spaceflight LiDAR Systems (SLS, normally with satellites as platforms; e.g., the Advanced Topographic Laser Altimeter System (ATLAS) carried on LCESat-2 satellite and (GLAS) carried on ICESat-1 satellite) [53].

This section focuses on applying LiDAR for individual tree biomass estimation (the reader is referred to the review of LiDAR applications for larger area forest characteristics [48] and the review on the advantages and disadvantages of the five main LiDAR systems for forest research [53]). Applications of TLS, ALS, UAV-LS and MLS are discussed here, but we exclude SLS due to its shortcomings in single parameter extraction.

\subsubsection{Terrestrial Laser Scanning (TLS)}

TLS is a ground-based LiDAR scanning system for measuring three dimensional (3D) forest structure using wavelengths in the visible or near-infrared domains [54]. Where it is impractical to measure forest biomass destructively, TLS offers a promising, non-destructive alternative with high spatial detail for $[55,56]$. Robust allometric algorithms significantly improve AGB estimation [57], but traditional forest biomass estimation based on allometry is affected by low accuracy measurements, especially for large trees (at the individual tree level) [58], and varies among tree species, stand densities, stand ages, environmental conditions and management practices [3,14,15,17,43,44]. TLS-derived biomass data, capturing large areas and spatial variability, expands sampling for allometric model and AGB model calibration, complementing traditional forest inventory methods to measure abiotic and biotic effects [56]. TLS-derived forest structure parameters are treated as ground validation of forest biomass models at large scales [56]. TLS has great potential to extract $\mathrm{DBH}$, tree height, stand density, leaf area index (LAI), leaf angle distribution, basal area, effective number of layers and AGB at both plot and individual tree scales $[54,56,59,60]$.

For forest biomass estimation from TLS at the single tree scale, discrete-return instruments are more popular than full-waveform instruments due to expense considerations. Some studies indicate that full-waveform TLS gives similar results as discrete-return TLS (Riegal VZ-400) for single trees [61]. Preprocessing of data acquired from these two instruments is significantly different. Preprocessing steps for full-waveform TLS-acquired data include identifying one or multiple hits with peak return energy, converting those hits to reflectance and recording these as points with coordinates and attributes [62]. The preprocessing of discrete-return TLS-acquired data focuses on filtering to reduce noise from terrain and intensity [63]. Point cloud data with high quality are generated from both TLS forms for future identification of forest structures at the single tree scale.

A growing number of studies have used TLS point cloud datasets to measure stand volume and AGB through a variety of tree reconstruction models [56]. Tree volume and AGB estimation at the individual tree scale strongly rely on trees being accurately delineated and segmented, and great efforts were made in this work to improve model accuracy to this end. In early models, only cylindrical sections were identified in TLS point clouds because tree stand volumes were estimated based on simple tree stem models [64]. Quantitative Structure Model (QSM) and Outer Hull Model (QHM) were widely used for trunk volume estimation $[57,65]$. Researchers later added leaf and branch components (i.e., unreplaceable components for AGB of individual trees) into the reconstruction to 
develop a voxel method of 3D reconstructions of individual trees [66]. Olsen et al. (2016) developed a high-fidelity tree voxel model (VoxLAD) for the TLS point cloud to improve the accuracy of canopy segmentation at the single tree scale [61]. Wichmann et al. (2018) reported an $80 \%$ improvement in single tree delineation accuracy for interlinked tree crowns using hemispherical photographs as reference data [63]. Tang et al. (2015) developed a photorealistic 3D reconstruction technique from TLS point clouds with high efficiency and accuracy without the need to first segment leaves and branches [67]. Wu et al. (2015) developed a comparative shortest-path algorithm (CSP) for both trunk detection and crown segmentation that significantly improved the accuracy of single tree segmentation [68].

Along with the development of point cloud processing, techniques can also extract single tree components from TLS point clouds; in particular, leaves (i.e., important for photosynthetic processes and a large part of AGB) [54,57]. Procedures for separating AGB components from TLS point clouds are, first, to separate leaves and woody parts, then partition woody parts (e.g., stump and crown), and finally further divide wood point clouds into stump meshing, stem and branch [56]. It is still challenging to accurately and automatically segment leaf and wood, stump and crown from TLS point clouds [56]. The separation of leaf and wood from single tree point clouds has been attempted using TLS by developing a generic, unsupervised method (LeWoS) [54] and combining unsupervised classification of geometric features and shortest path analysis [69].

Although TLS estimates forest AGB at the individual tree level with high accuracy (particularly true for distinguishing biomass among tree components), the acquisition of TLS point clouds is time consuming [58] and occlusion effects still limit the processing efficiency for estimating AGB at the single tree scale [70]. This is not suitable for measuring single tree AGB in large study areas. It is also a challenge to use TLS to estimate AGB at individual tree scales in dense forests, especially at the leaf-on stage, because occlusion and overlap contrast among neighbor tree crowns [56]. Moreover, TLS is limited in its ability to distinguish upper canopy structure, especially in forests with complex vertical structures. However, TLS with multiple scans is an improvement over TLS with a single scan [70]. Therefore, some studies have extracted upper canopy structure using ALS point clouds, and lower canopy structure and DBH from TLS point clouds [65].

\subsubsection{Airborne Laser Scanning (ALS)}

ALS shows promise for forest biomass mapping over large areas (i.e., regional or national scales) because of its ability of measuring 3D structures [71]. This is an improvement over TLS in this function. For example, ALS data coverage of Finland in 2008 not only provided a detailed terrain elevation map, but also collected explanatory variables for AGB estimation [72]. ALS is also superior to TLS in canopy structure extraction, including crown size and form and dominant tree height [73]. Approaches for forest AGB estimation include both area-based and single tree-based approaches [73]. The area-based approach often uses statistical and empirical models of ALS-extracted structure metrics and deconstructive ground-based measurements [74]. Tree height, crown dimensions and other tree size attributes that are closely related to AGB estimation could be measured from ALS point clouds using individual tree detection and crown segmentation directly with high efficiency and accuracy [73].

Using single tree-based approaches with ALS point clouds for forest AGB biomass estimation usually relies on traditional allometric models [47,75]. Even though ALS is a promising technique to accurately and efficiently measure individual tree height, it remains a challenge to monitor DBH using ALS [6] with existing allometric tree volume models. Studies suggest that DBH estimation inaccuracy biases allometric models [75]. Vauhkonen et al. [75] studied individual tree biomass estimation in a mixed forest (Scots pine, Norway spruce and birch) and obtained root mean square errors (RMSE) of $13 \%$ for $\mathrm{DBH}, 3 \%$ for height and 31\% for volume. Researchers have tried two approaches to solve this problem: (1) estimate DBH from LiDAR-extracted tree size parameters (e.g., tree height) based on statistical models [11], and (2) use forest biomass algorithms that do not rely on 
DBH. Popescu [47] first introduced biomass allometric equations using tree height and crown diameters. However, Usoltsev et al.'s [76] comparative results show the accuracy of an allometric model with ALS-derived tree height and crown dimeter is significantly lower than that with ground-measured tree height and DBH. Fu et al. [77] built a statistical DBH model from crown projection area and tree height. Allouis et al.'s [12] research shows that crown projection area has good potential to estimate tree DBH and Anjin et al.'s [8] research indicates that crown diameter can also effectively estimate DBH. However, the bias of DBH estimation compared to other tree size parameters could introduce more errors to biomass allometric models. Therefore, Popescu et al. [47] established the concept of allometric algorithms for forest biomass estimation using ALS-derived tree size parameters including tree height, crown diameter, crown height and basal area. Popescu et al.'s results show that ALS-derived crown diameter alone explained $78 \%$ of the variation of tree biomass and $83 \%$ of the variation of tree volume [47]. Wan-Mohd-Jaafar et al. [78] estimated forest biomass using ALS-extracted crown diameter, crown height and tree height $\left(R^{2}=0.63\right.$ for AGB estimation at the individual tree scale). Giannico et al. [51] evaluated forest biomass based on ALS-derived basal area and tree height, improving the correlation $\left(R^{2}=0.81\right.$ for tree volume estimation and 0.77 for AGB estimation). Some studies also argue that multiple linear regression using ALS-derived geometric and statistical point metrics as explanatory variables is better than the existing allometric models using ALS-derived height and crown diameter as input parameters for AGB estimation for individual trees [71].

No matter which model was used for AGB or tree volume estimation for single trees, eventually, the accuracy of individual tree detection and crown segmentation was fundamental. Complexity of forest conditions, sparse ALS point density and inaccurate tree species identification can create uncertainty and lower the accuracy of tree detection and crown segmentation [74]. Determining single tree size attributes requires ALS with higher pulse density than area-based approaches, and the required point density also varies among forest ecosystems [73]. However, Kaartinen et al. [74] found that the ALS point density has less impact on individual tree crown segmentation than other methods. ALS-based individual tree detection has a varying accuracy, from 40 to $93 \%$, but the portion of variation caused by forest condition or the methods remains unclear [74].

The effects of forest conditions on individual tree detection and crown segmentation will be discussed in Section 2.3. Here, we focus on the methods and algorithms for tree detection and crown segmentation for individual trees. In early studies, the accuracy for ALS-based individual tree detection and crown segmentation ranged from 29.7 to 48.3\% [72]; the development of the Canopy Height Model (CHM) significantly improved the accuracy for tree detection at the single tree level [79]. CHM is associated with the canopy maxima algorithm to detect tree tops from the rasterized canopy heights from ALS point clouds [80]. High commission or omission rates might bring basis into individual tree detection outputs from CHM due to forest structure complexity and different tree species [81]. Therefore, previous studies tried to use marker-based watershed algorithms to improve the accuracy of individual tree detection based on CHM [82]. Zhang et al. [81] proposed a hybrid framework using ALS point clouds based on the configurations from CHM. This significantly reduced commission errors produced by local maxima filtering and increased overall accuracy by $10 \%$. To improve its accuracy, manually set thresholds and parameters were normally required [80]. To improve the processing accuracy and provide comparable results among locations, automatic individual tree detection was attempted. Heurich [83] delineated individual tree crowns using automatic recognition for ALS-derived tree height and crown diameter that achieved an overall accuracy of $79.6 \%$ for individual tree detection from the upper canopy. Dong et al. [80] developed an automatic single tree detection method using gradient orientation clustering (GOC) based on the rasterized CHM from ALS point clouds, significantly improving accuracy. Other efforts were made to detect individual trees using ALS fusion and optical imagery [73], alternative methods (e.g., nearest-neighbor estimation [84]), ALS-derived shape metrics and structure parameters as inputs for classification algorithms (e.g., k-Most Similar Neighbor (K-MSN) 
and the Random Forest (RF) [75]). Some research has estimated branch biomass using empirical models of ALS-extracted crown volume and dried weights of deconstructed tree branches based on the results of individual tree detection and segmentation, with a root mean square error (RMSE) of 35\% [85].

Further studies improved algorithms and methods for individual tree detection and crown segmentation for higher accuracy of AGB estimation from ALS for individual trees. However, height estimation still varies in complex canopy structures and topography conditions due to low vertical point density [73]. More importantly, most of the current techniques for single tree detection are inefficient for dense forest ecosystems due to high commission and omission rates [80]. Therefore, researchers take advantage of both ALS (i.e., extracting tree heights, number of trees and tree crown width) and TLS (i.e., DBH, stand volume and tree height) for AGB estimation $[65,79,86]$. Synergies of ALS and TLS data have been shown to improve AGB and stand volume estimation [72,84,86,87]. In the future, more studies should explore the difference and complementarities between ALS and TLS because both derive tree size and structure parameters at the individual tree scale.

\subsubsection{Unmanned Aerial Vehicle Laser Scanning (UAV-LS)}

UAV-LS components are quite similar to ALS; however, Unmanned Aerial Vehicles (UAV) fly at much lower altitudes of 50-300 m (ALS acquired point cloud data at a higher altitude of 500-3000 m) [53]. UAV-LS is more flexible than ALS, more convenient, provides higher point density and lower cost [88], but covers less area. Compared to ALS, UAV-LS acquire point clouds with much higher point density horizontally and vertically [89], which enhances the capacity of point clouds for distinguishing tree crowns [65].

However, the challenge for UAV-LS applications for forest biomass estimation is single tree detection and segmentation, forcing individual tree research to sometimes be reported at plot, tree stand or regional scales [6]. The methods for individual tree detection and crown segmentation for ALS point clouds have the ability to be used for UAV-LS point clouds. There are two main categories of methods for individual tree detection and crown segmentation. The first is CHM-based, which applies CHM to search windows (width of searching window is less than canopy diameter) to find canopy maxima and identify tree locations first and then separate individual trees based on segmentation algorithms $[6,8,11,34,90]$. The second is a voxel-based method using cluster analysis (e.g., k-mean clusters) on point clouds of LiDAR data in voxel space to first segment all individual trees and then search local maxima in 3D clusters as single tree locations $[77,89,91]$. Wu et al. [88] applied CHM-based models for individual tree detection and delineation first, and achieved an accuracy of $0.77-0.83$ for canopy cover estimation based on the tree segmentation. Dalla Corte et al. [92] performed individual tree detection with a local maximum filter algorithm in R package "lidR" from rasterized CHM generated from UAVLS point clouds. Based on the individual tree detection and segmentation results, Dalla Corte et al. [92] applied machine learning methods, including Support Vector Regression, Random Forest, Artificial Neural Networks and Extreme Gradient Boosting, for DBH estimation (i.e., with a RMSE of 15\%), height (i.e., with a RMSE of 9\%) and stand volume (i.e., with a RMSE of 29\%) at a single tree scale. Dalla Corte et al. [93] estimated DBH and tree height based on individual tree detection and segmentation outputs using voxel-based methods, resulting in an RMSE of $11.3 \%$ for DBH and $7.9 \%$ for tree height. Chen et al. [94] used voxels of various tree species as training data for the PointNet deep learning to identify the tree crowns at the voxel scale and then accurately depict the boundaries of individual tree crowns based on gradient information of canopy height.

Although UAV-LS-based individual tree detection and segmentation have satisfied accuracy [91], both methods perform inefficiently with much lower accuracy for individual tree detection and delineation for forest ecosystems with irregular canopy shape and multiple stems (e.g., broadleaf forests instead of coniferous forests) [91,95-97]. It significantly improves the performance of individual tree detection and segmentation based on UAV-LS to apply a maker-controlled watershed segmentation algorithm [95]. Yin and Wang [95] 
obtained a delineation accuracy of $46 \%$ for mangrove forests with high clumping density and limited height difference between adjacent mangroves. Picos et al. [96] explored new individual tree segmentation methods based on stem distributions that achieved a detection rate of 103.7 and $113.6 \%$.

Another challenge for single tree detection using UAV-LS comes from the crown top, as the canopy shifts from the actual tree location, particularly among broadleaf tree species. It remains difficult to match UAV-LS-extracted tree locations with field-collected validation tree locations [6]. Edson and Wing's [5] research in the North American boreal forest shows that extracted single tree locations from LiDAR shift 2.05-2.31 m compared to field-collected single tree locations through GPS devices.

In conclusion, it will be necessary for future research to develop new methods to resolve the shortcoming of single tree detection and segmentation for forest ecosystems with complex canopy or understory structures (e.g., broadleaf forests or natural forests with various ages). Moreover, alternative methods are needed to detect tree location and field data collection to solve location shifting issues. Current methodologies of AGB estimation from UAV-LS point clouds still rely on allometric algorithms [98]; therefore, automatic and direct extraction methods of individual tree AGB will be necessary.

\subsubsection{Mobile Laser Scanning (MLS)}

MLS collects point cloud data near the ground, mainly under the forest canopy, which is similar to TLS. Compared to TLS, the success of using MLS allows for acquiring 3D point cloud data in a large area efficiently [70]. The two types of MLS are Vehicle-borne Laser Scanning (VLS) and Backpack Laser Scanning (BLS). Currently, the studies of both VLS and BLS are in the stage of individual tree detection and segmentation because it is fundamental for the estimation of tree size parameters and AGB for individual trees. Yan et al. [99] proposed a new method (i.e., a concave hull by slices method) for individual tree segmentation, which obtained better accuracy than five existing methods including manual measurement, 3D convex hull, 3D alpha shape, convex hull by slices and a voxelbased method. BLS arouses more and more interest, currently because it is superior to both TLS and VLS due to its flexibility to collect close-by measurements in all directions in a timely manner [100]. Lu et al. [98] used seed points generated from BLS data for individual tree detection from UAV-LS, which significantly improved the accuracy for individual tree detection and segmentation. Xie et al.'s [100] results indicate that a vertical thickness of $30 \mathrm{~cm}$ for point cloud slices was best for DBH estimation (i.e., R square was 0.89 when compared with manual measurements) at the single tree level from BLS point clouds and DBH extracted from BLS was smaller than that from manual measurements. Zhang et al. [101] compared the potential of TLS and BLS for the estimation of apple tree branches and the results show that TLS is better in the estimation of branch length and BLS is better for the number counting of branches. However, the application of BLS is still in an early stage, and its measurement accuracy and error sources have not been systematically explored [100].

\subsection{The Impact of Forest Conditions and Species on AGB Estimation at the Individual Tree Scale} Based on LiDAR Data

\subsubsection{Effects of Forest Site Conditions}

Forest site conditions have a large influence on biomass monitoring accuracy at the individual tree scale because environmental noise affects the accuracy of LiDAR-extracted biophysical parameters. The estimation accuracy is often limited by complex tree structures (leaves and branches), flowers and forest understory herbs [102]. Therefore, it is important to determine how environmental factors influence biomass estimation by UAV LiDAR data and establish new methods to control for the effects of forest site condition. Stand age, stand density, upper canopy structure (flat or irregular) and forest understory vegetation might all influence forest biomass estimation by UAV LiDAR at the individual tree scale $[90,91]$. This, in turn, could result in inaccurate tree counts and reduce the extraction accuracy 
of biophysical parameters for individual trees. Yu et al.'s [103] research based on ALS data resulted in $69 \%$ accuracy for single tree detection under various forest conditions (i.e., different site types, stand density and stand age). Kaartinen et al. [74] summarized the accuracy of single tree detection from LiDAR data in the boreal forest and found that stand age has a large impact on the detection accuracy of single trees from LiDAR data. Edson and Wing's [5] research also shows that stand age affects the accuracy of single tree detection from LiDAR data. Vauhkonen et al. [104] studied single tree detection from LiDAR data for forest ecosystems with complex structures and their results show that stand density and tree structure influence the accuracy of single tree detection. Gregoire et al.'s [102] research indicates that the complex structure of forest understory vegetation significantly reduces the estimation accuracy of forest biomass at the individual tree scale using LiDAR data. Goldberg et al.'s [34] research indicates that single tree detection for heights exceeding $10 \mathrm{~m}$ (detection accuracy: 75\%) is more accurate than for stem heights less than $10 \mathrm{~m}$ (detection accuracy: $66 \%$ ) based on ALS data. Therefore, studying the impact of stand age, stand density and structure of understory vegetation on single tree detection and forest biomass at the individual tree scale based on UAV LiDAR is a promising research direction.

\subsubsection{Effects of Forest Types and Tree Species}

Numerous tree detection, 3D reconstruction and crown segmentation techniques for single trees have been developed using ALS, TLS and UAV-LS. However, accurate single tree detection and crown segmentation remain a challenge due to tree crown intersection and irregular crown shape [68]. Complex crown intersection and irregular crown shapes are determined among forest types (e.g., natural forest ecosystems or plantations, deciduous forests, coefficient forests, mixed forests or tropical evergreen forests) and tree species (e.g., Scots pine, Norway spruce or European beech (Fagus sylvatica)) with different canopy structures. Previous studies indicated that QSM based on TLS data systematically overestimated stand volumes in tropical evergreen forests [56]. Tao et al.'s [68] research shows that single tree segmentation from TLS has higher accuracy in coniferous forests (i.e., kappa coefficient of 0.93) than broad-leaved forests (i.e., kappa coefficient of 0.83). Similar conclusions have been drawn, that single tree segmentation of coniferous species has better accuracy than that of deciduous or evergreen broad-leaved species-based UAV-LS and ALS point cloud data, especially for the broad-leaved forest canopy in the growing season due to irregular and overlapping shapes [98]. Liu et al.'s [105] research reveals that single tree segmentation based on ALS is most accurate in coniferous forests (93\%), moderately accurate in coniferous and broadleaf mixed forest (86\%) and is least accurate in broadleaf forest (60\%). Heurich et al. [83] performed single tree delineation in Bavarian Forest National Park (i.e., mixed forests of Norway Spruce and European Beech, in Germany) and the results show that conifers provided greater accuracy than deciduous species. Ene et al. [82] detected single tree locations in highly heterogeneous natural boreal forests with a detection accuracy ranging from 46 to $50 \%$. Their results also indicate that tree height estimation was more accurate for deciduous tree species than coniferous species (i.e., Scots pine and Norway spruce), while the estimated crown diameter was more accurate for Scots pine and deciduous species than Norway spruce [82]. Kankare et al.'s [71] research shows that AGB estimation is more accurate for Scots pine (i.e., with an RMSE of $26.3 \%$ ) than Norway spruce (i.e., with an RMSE of 36.8\%) based on ALS point cloud data. Brede et al.'s [58] results indicate that UAV-LS-based AGB estimation at the single tree level is more reliable for mature beech and oak species than dense Norway Spruce stands. Chen et al. [94] compared the performance of UAV-LS on single tree detection for four forest types and achieved a detection rate of 0.9 for nursery base, 0.85 for monastery garden, 0.82 for defoliated forest and 0.8 for mixed forest, which also indicates that the complexity of forest structure reduces the detection accuracy for individual trees. 
2.3.3. Integrating Optical Images to Reduce the Effects of Tree Species and Forest Conditions

In the early uses of LiDAR to estimate forest biomass, Popescu et al. [52] applied data fusion to ALS and hyperspectral data to improve accuracy. Recently, many more studies integrated hyperspectral data for tree species detection and crown boundary identification to improve the accuracy of AGB estimation at the plot scale. Research into tree height extracted from ALS and horizontal heterogeneity derived from hyperspectral images has applied statistical models to field-measured forest biomass [106-108]. Dalponte et al.'s [109] research indicated that tree species detections from airborne hyperspectral data significantly improved ALS-based forest AGB estimation at the plot scale. Ediriweera et al.'s [110] research also shows multispectral data are effective at identifying crown boundaries that enhance the potential for ALS to estimate forest AGB at the plot scale. Although many studies attempt to combine optical images with high spatial resolution and ALS data to improve the accuracy of forest biomass estimates, few studies have been successful at the individual tree scale [111] or using UAV-LS data [91]. Therefore, further research integrating the strength of UAV optical and LiDAR remote sensing to monitor forest biomass at the individual tree scale would be of value.

\subsection{Challenges to Current Methods}

Although the four primary types of LiDAR data have proven promising for some aspects of AGB estimation in individual tree detection, they still have shortcomings (advantages and disadvantages for TLS, ALS, UAV-LS and BLS are organized in Table 1). In conclusion, there remain five challenges to apply LiDAR remote sensing to forest biomass estimation at individual tree scales (Figure 1): (1) allometric equations (i.e., ecological methods of forest biomass estimation based on samples at the individual tree scale) are regionally specific and inapplicable for other regions due to tree species, environmental factors, management policies, stand density and age, (2) DBH (a key factor of tree volume and biomass with tree height, crown diameter and crown height), a common input parameter for biomass allometric equations, is difficult to measure with ALS and UAV-LS data, (3) despite UAV-LS resolution being optimal for biomass estimation at single tree scales, measurement accuracy for single tree detection and segmentation is affected by tree species with complex canopy structures and overlapping with neighbor canopies, (4) forest site conditions add noise to LiDAR-extracted tree size information and (5) there are relatively few examples of integrating the advantages of UAV-LS and BLS data, or UAV-LS and TLS data to monitor AGB at the individual tree scale.

Table 1. Advantages and disadvantages of TLS, ALS, UAV-LS and BLS for AGB estimation for individual trees.

\begin{tabular}{|c|c|c|}
\hline \multirow[t]{2}{*}{ TLS } & Strength & $\begin{array}{l}\text { - } \\
\text { - } \quad \text { current estimation of } \mathrm{DBH} \text {, tree height and stand volume at individual tree scale } \\
\text { - } \\
\text { distinguish biomass for different components of single trees including branches, stem } \\
\text { and leaves }\end{array}$ \\
\hline & Weakness & $\begin{array}{l}\text { - } \quad \text { time consuming for both data acquisition and processing due to occlusion effects } \\
\text { - } \quad \text { lack of capacity for large-scale mapping for forest biomass } \\
\text { - } \quad \text { inability to capturing upper canopy structure for dense and complex forests }\end{array}$ \\
\hline \multirow[b]{2}{*}{ ALS } & Strength & $\begin{array}{l}\text { - } \quad \text { forest 3D structure over large area in a spatially contiguous manner } \\
\text { - } \quad \text { tree height estimation in both plot and single tree levels } \\
\text { - } \quad \text { CHM-based methodology for individual tree detection and crown segmentation }\end{array}$ \\
\hline & Weakness & $\begin{array}{l}\text { - the integration of ALS-derived tree size parameters with allometric models } \\
\text { - } \quad \text { inability to estimate DBH with the restriction of point density } \\
\text { - coarse accuracy of current methodology for single tree detection and crown segmentation } \\
\text { for various forest conditions and tree species with complex canopy structure }\end{array}$ \\
\hline
\end{tabular}


Table 1. Cont.

\begin{tabular}{|c|c|c|}
\hline \multirow[b]{2}{*}{ UAV-LS } & Strength & $\begin{array}{l}\text { - } \quad \text { higher pulse density, lower cost with more details of forest 3D structures compared to ALS } \\
\text { - } \quad \text { matching most single tree detection and crown segmentation methodology based on ALS }\end{array}$ \\
\hline & Weakness & $\begin{array}{l}\text { - less coverage than ALS } \\
\text { - the accuracy of single tree detection and segmentation varies from different tree species and } \\
\text { site conditions } \\
\text { DBH estimation at individual tree level }\end{array}$ \\
\hline \multirow{2}{*}{ BLS } & Strength & $\begin{array}{l}\text { - } \quad \text { higher efficiency for data collection and processing than TLS } \\
\text { - } \quad \text { matching the advantages of TLS }\end{array}$ \\
\hline & Weakness & $\begin{array}{l}\text { - } \quad \text { research in the early stage } \\
\text { - } \quad \text { the measurement accuracy and error sources are not systematically explored }\end{array}$ \\
\hline
\end{tabular}

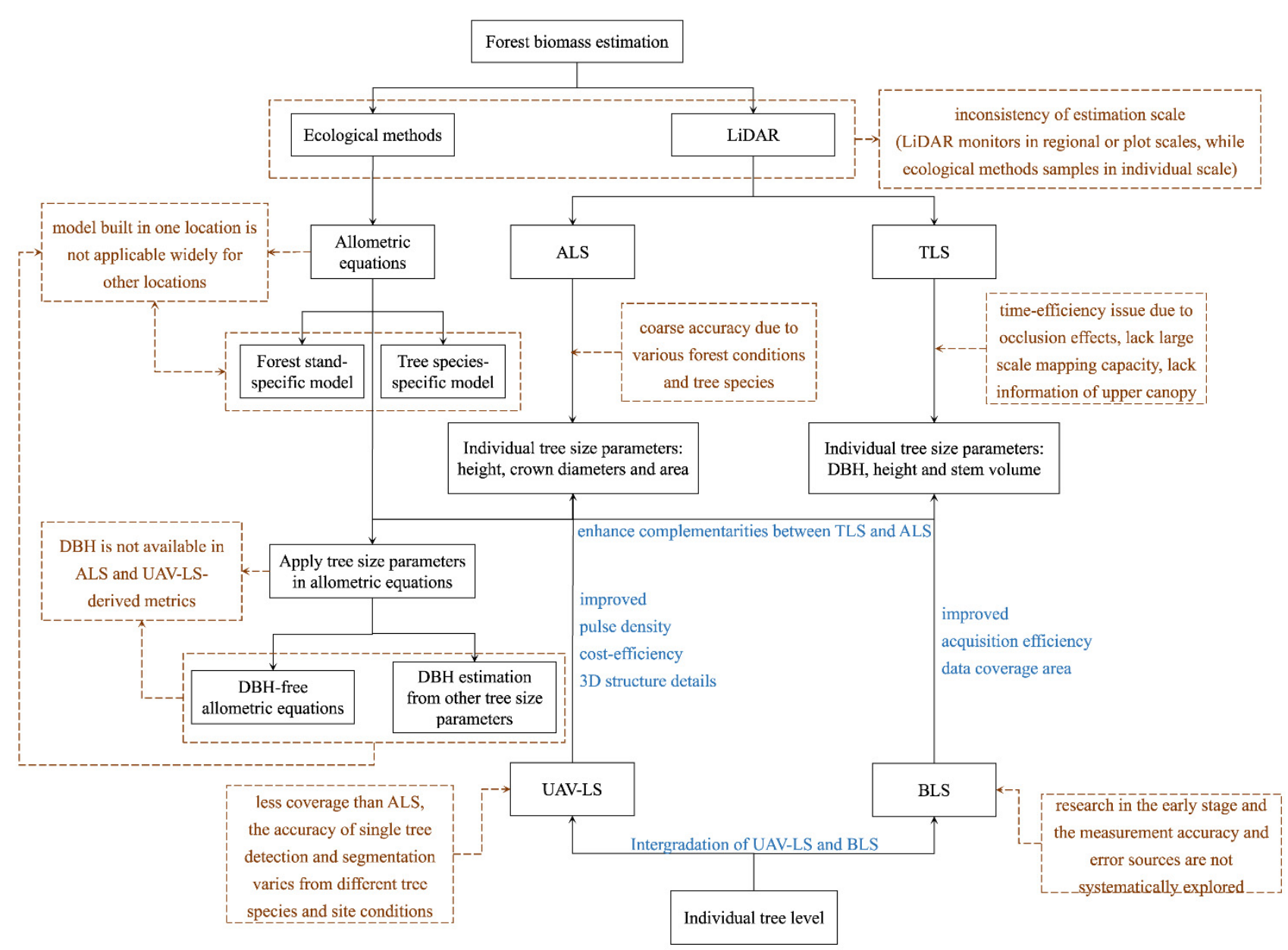

Figure 1. Challenges of current methodology for applying remote sensing to forest biomass estimation at the individual tree scale.

\section{Future Directions for Forest Biomass Estimation at the Individual Tree Scale Using Remote Sensing}

3.1. Improving the Accuracy of Single Tree Detection and Segmentation with Automatic Processing Capacity Based on UAV-LS Data

Thanks to the development of LiDAR data mounted on UAV, it is possible to monitor forest biomass at the individual tree scale. However, current methods initially developed based on ALS and TLS data (i.e., CHM-based methods and voxel-based methods) are insufficient for single tree detection and segmentation from UAV-LS, especially for broadleaved forests with complex canopy structure and crown overlapping.

We tested the CHM-based method and voxel-based method in a poplar (Populus deltoids and Populus euramericana) plantation during peak growing season to better illustrate 
the challenges and future direction for UAV applications in broadleaf forest (Figure 2). The CHM-based method results in an overestimation of the number of individual trees compared to the actual number (Figure 2a: each red dot is the result of a single tree), which also relies on manually setting the search window width for local maxima filtering. Because one single broadleaf tree with a much flatter canopy than coniferous species might contain more than one local maxima for each branch, it could be identified as several trees (Figure 2a). The voxel-based method results in higher accuracy of single tree detection (Figure 2b: each red dot identifies one tree) and single tree segmentation (Figure 2c: each color cluster is one segment for an individual tree). The voxel-based method results in fewer individual trees, but still an overestimate of the actual number (Figure 2a,b).
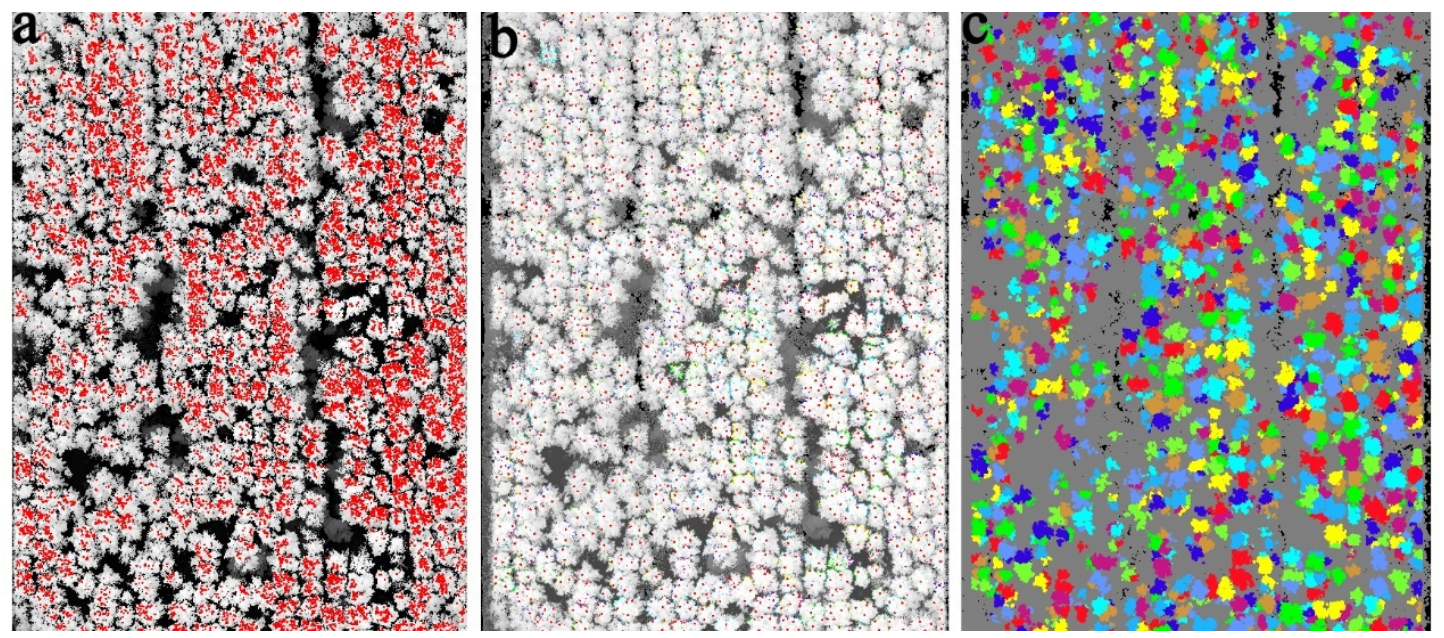

Figure 2. Single tree detection and segmentation in a poplar plantation using UAV-LS data. (a) Single tree detection results using CHM-based method; each red dot is predicted to be a single tree. (b) Single tree detection results using the voxel-based method; each red dot is a predicted location of each single tree. (c) Single tree segmentation results using single tree detection results from $(\mathbf{b})$ the second method where each color cluster is one segment for an individual tree.

To overcome this challenge, studies have used marker-based watershed algorithms to improve the individual tree detection accuracy of CHM-based approaches from ALS point clouds [82]. This has high capacity to be applied in UAV-LS data. Seed points or markers have great potential to significantly improve the accuracy of CHM-based methods for single tree detection; however, they often lack automatic processing and batch processing capacity due to their need for human intervention. Recent studies significantly improved the overall accuracy of single tree detection from UAV-LS data based on the automatically extracted seed points from BLS [98]. Therefore, future research in this field could align single tree detection and segmentation with high accuracy and automatic processing capacity. Another future direction may be to improve UAV-LS-based single tree detection and segmentation by integrating crown boundary and tree species information [91] extracted from hyperspectral or multispectral images with high spatial resolution.

\subsection{Improving the Accuracy of LiDAR-Derived Tree Size Parameters}

Unlike forest biomass estimation at the forest stand level, individual tree biomass is directly related to tree size parameters $(\mathrm{DBH}$, tree height, crown diameter and crown height). In the literature, tree height, crown diameter and crown height have been extracted from LiDAR data with satisfactory accuracy, especially in coniferous forests. However, accuracy is often influenced by site conditions, forest and tree structure and understory shrubs and herbs. Moreover, the accuracy of single tree detection and segmentation has a direct impact on the accuracy of tree size information extraction at the individual tree scale. Therefore, separating the point clouds (from LiDAR) for various forest components (i.e., tree and understory) after single tree detection and segmentation will be a productive direction to improve the accuracy for extracting key forest and tree parameters. Optical 
remote sensing has the ability to differentiate forest components. UAV optical data provide optimal spatial resolution to extract forest information at the individual tree scale [112]. However, UAV optical data only provide information for the forest canopy and it is a challenge to use it to extract forest understory information. Therefore, a potential future direction would be to estimate 3D structure based on UAV optical data to help identify different forest components to improve the accuracy of tree height, crown diameter and crown height information. In the literature, Agisoft PhotoScan software [113] has proven to be useful to build 3D structures based on optical images taken from a variety of angles from various altitudes (Figure 3).

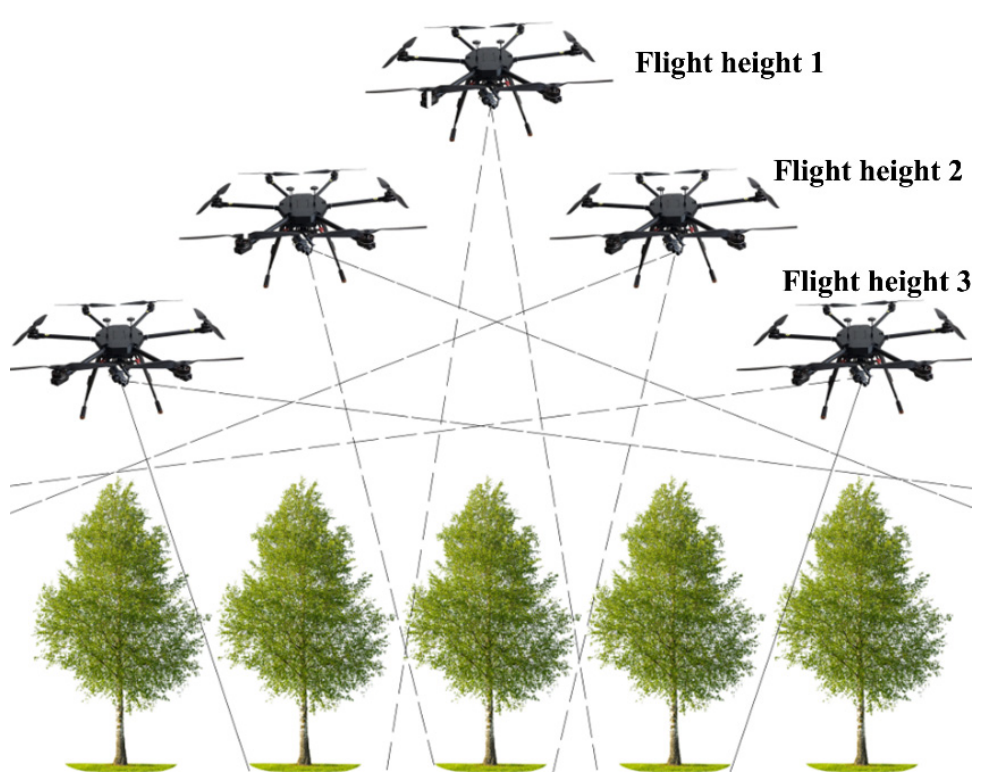

Figure 3. Insight for acquiring UAV optical images of different angles to construct 3D structure.

\subsection{AGB Estimation at the Individual Tree Scale by Integrating UAV-LS and BLS}

Previous studies have mainly focused on exploring the advantages and disadvantages of TLS, ALS, UAV-LS and BLS for AGB estimation for individual trees (Table 1). Research conducted a cross comparison among different LiDAR types. Giannetti et al. [114] compared the capacity of a hand-held mobile laser scanner (HMLS), TLS, ALS and the combination of TLS and ALS for single tree detection and the estimation of DBH, tree height, crown base height and crown projection area. Their results indicate that TLS had greater accuracy for tree height estimation than HMLS and significantly increased the performance of tree height and crown projection area estimation from TLS data by integrating ALS data [114]. Bazezew et al. [65] take the advantage of ALS-derived single tree location and TLS-derived DBH for AGB estimation in tropic forests. However, the advantages and disadvantages of UAV-LS and BLS on AGB estimation or different biomass components (i.e., stems, branches and leaves) have not been studied enough for single trees. Brede et al. [58] found UAV-LS, compared to the capacity of TLS, reliably estimated tree volume for trees with DBH larger than $30 \mathrm{~cm}$ in a Dutch temperate forest (i.e., mixed with coniferous and deciduous species). Combining UAV-LS and BLS might be a successful future direction for AGB estimation for single trees. BLS and UAV-LS are both emerging remote techniques with unprecedented detailed 3D information for reconstructing forest structure [98,100,115]. However, few studies have tried this. This direction may allow the combination of UAV-LS-derived upper canopy parameters and BLS-derived lower canopy information, and data fusion between UAV-LS and BLS point clouds. Polewski et al. [115] explored the capacity of the coregistration of UAV-LS and BLS. Based on the advantages of UAV-LS and BLS it appears possible to remotely measure all tree size parameters at the single tree level with higher accuracy, suggesting a future direction of study based on the combination of UAV-LS and BLS for forest AGB estimation at the scale of individual trees. 


\subsection{The Effects of Forest Structure and Site Condition on AGB Estimation at the Individual Tree Scale}

Forest site condition (e.g., understory vegetation) and forest structure (i.e., stand age, stand density and canopy structure) introduce noise that reduces the accuracy of forest biomass estimation at the individual tree scale using LiDAR data. Therefore, future research should focus on understanding how those factors influence single tree detection and segmentation as well as extracting tree size information with UAV-LS due to its ability to produce detailed forest structure information more effectively than using ALS data. Based on this information, optimal methods can be determined for single tree detection and segmentation, measurement of tree height, $\mathrm{DBH}$, crown height and crown diameter and biomass estimation of individual trees in diverse ecosystems.

\section{Conclusions}

In conclusion, LiDAR data has great potential to monitor forest biomass because of its ability to extract tree size parameters (height, crown diameter and crown height). Currently, LiDAR techniques for research of individual trees have been improved by using UAV-LS and BLS compared to ALS and TLS. Although UAV-LS data has optimal spatial resolution for forest AGB estimation at the individual tree scale, it is not widely applied to single trees because of low accuracy in single tree detection and segmentation, especially in broadleaf forests or in forests with complex structure; noise affects UAV-LS-derived tree size information and makes DBH undetectable. Therefore, it is necessary to develop new methods for single tree detection and segmentation with high accuracy and automatic processing capacity under variable forest conditions. It has been suggested to integrate the information from crown boundaries and tree species information extracted from high resolution optical imagery (e.g., UAV optical images) to improve accuracy for single tree detection and segmentation from UAV-LS. Moreover, a more complete understanding of forest structure and site condition effects on LiDAR applications for forest biomass estimation using single trees is a path forward to improve predictions of stand dynamics using individual tree biomass. Due to the success of the combination of ALS-derived upper canopy structure and TLS-derived lower canopy information, the integration of new developed BLS and UAV-LS techniques is identified as a future direction for forest AGB estimation where individual tree detection is warranted. Research in this direction could continuously explore the advantages and disadvantages of UAV-LS and BLS for research regarding single tree detection, or focus on the fusion of UAV-LS and BLS point cloud data to automatically extract stem volume and crown volume.

Author Contributions: The contribution for D.X. was to come up with the initial ideas and write the manuscript. The contribution of H.W. was to help with organizing the literature. The contributions for W.X., Z.L. and X.X. were to guide the organization of initial ideas and revise the manuscript. All authors have read and agreed to the published version of the manuscript.

Funding: This study was funded by the National Natural Science Foundation of China (41901361), the Six Talent Peaks Project in Jiangsu Province (TD-XYDXX-006), the Natural Science Foundation of Jiangsu Province (BK20180769) and the Major Basic Research Project of the Natural Science Foundation of the Jiangsu Higher Education Institutions (18KJB180009) for financial support.

Institutional Review Board Statement: Not applicable.

Informed Consent Statement: Not applicable.

Data Availability Statement: Not applicable.

Conflicts of Interest: The authors declare no conflict of interest.

\section{References}

1. Hofstad, O. Review of biomass and volume functions for individual trees and shrubs in southeast africa. J. Trop. For. Sci. 2005, 17, 151-162.

2. Parresol, B.R. Assessing tree and stand biomass: A review with examples and critical comparisons. For. Sci. 1999, 45, 573-593. 
3. Shrestha, D.B.; Sharma, R.P.; Bhandari, S.K. Individual tree aboveground biomass for castanopsis indica in the mid-hills of nepal. Agrofor. Syst. 2018, 92, 1611-1623. [CrossRef]

4. Ozcelik, R.; Eraslan, T. Two-stage sampling to estimate individual tree biomass. Turk. J. Agric. For. 2012, 36, 389-398.

5. Edson, C.; Wing, M.G. Airborne light detection and ranging (lidar) for individual tree stem location, height, and biomass measurements. Remote Sens. 2011, 3, 2494-2528. [CrossRef]

6. Allouis, T.; Durrieu, S.; Vega, C.; Couteron, P. Stem volume and above-ground biomass estimation of individual pine trees from lidar data: Contribution of full-waveform signals. IEEE J. Sel. Top. Appl. Earth Obs. Remote Sens. 2013, 6, 924-934. [CrossRef]

7. Hember, R.A.; Kurz, W.A. Low tree-growth elasticity of forest biomass indicated by an individual-based model. Forests 2018, 9 , 21. [CrossRef]

8. Anjin, C.; Yongmin, K.; Yongil, K.; Yangdam, E. Estimation of individual tree biomass from airborne lidar data using tree height and crown diameter. Disaster Adv. 2012, 5, 360-365.

9. Bortolot, Z.J.; Wynne, R.H. Estimating forest biomass using small footprint lidar data: An individual tree-based approach that incorporates training data. ISPRS J. Photogramm. Remote Sens. 2005, 59, 342-360. [CrossRef]

10. Zeng, W.; Fu, L.; Xu, M.; Wang, X.; Chen, Z.; Yao, S. Developing individual tree-based models for estimating aboveground biomass of five key coniferous species in china. J. For. Res. 2018, 29, 1251-1261. [CrossRef]

11. Kim, Y.; Chang, A.; Kim, Y.; Song, J.; Kim, C. Estimation of forest biomass from airborne lidar data as measures against global warming-individual tree unit and forest stand unit. Disaster Adv. 2012, 5, 295-299.

12. Allouis, T.; Durrieu, S.; Vega, C.; Couteron, P. Exploiting fullwavefrom lidar signals to estimate timber volume and aboveground biomass of individual trees. In Proceedings of the 2011 IEEE International Geoscience and Remote Sensing Symposium, Vancouver, BC, Canada, 24-29 July 2011; pp. 1251-1254.

13. Krofcheck, D.J.; Litvak, M.E.; Lippitt, C.D.; Neuenschwander, A. Woody biomass estimation in a southwestern u.S. Juniper savanna using lidar-derived clumped tree segmentation and existing allometries. Remote Sens. 2016, 8, 453. [CrossRef]

14. Fu, L.; Zeng, W.; Zhang, H.; Wang, G.; Lei, Y.; Tang, S. Generic linear mixed-effects individual-tree biomass models for pinus massoniana in southern china. South. For. 2014, 76, 47-56. [CrossRef]

15. Oliveira, N.; Rodriguez-Soalleiro, R.; Perez-Cruzado, C.; Canellas, I.; Sixto, H. On the genetic affinity of individual tree biomass allometry in poplar short rotation coppice. Bioenergy Res. 2017, 10, 525-535. [CrossRef]

16. Zeng, W.; Duo, H.; Lei, X.; Chen, X.; Wang, X.; Pu, Y.; Zou, W. Individual tree biomass equations and growth models sensitive to climate variables for larix spp. In china. Eur. J. For. Res. 2017, 136, 233-249. [CrossRef]

17. Wang, X.; Bi, H.; Ximenes, F.; Ramos, J.; Li, Y. Product and residue biomass equations for individual trees in rotation age pinus radiata stands under three thinning regimes in new south wales, australia. Forests 2017, 8, 439. [CrossRef]

18. LeBauer, D.S.; Treseder, K.K. Nitrogen limitation of net primary productivity in terrestrial ecosystems is globally distributed. Ecology 2008, 89, 371-379. [CrossRef] [PubMed]

19. Way, D.A.; Oren, R. Differential responses to changes in growth temperature between trees from different functional groups and biomes: A review and synthesis of data. Tree Physiol. 2010, 30, 669-688. [CrossRef]

20. Bugmann, H.; Bigler, C. Will the $\mathrm{CO}_{2}$ fertilization effect in forests be offset by reduced tree longevity? Oecologia 2011, 165, 533-544. [CrossRef]

21. Friend, A.D.; Lucht, W.; Rademacher, T.T.; Keribin, R.; Betts, R.; Cadule, P.; Ciais, P.; Clark, D.B.; Dankers, R.; Falloon, P.D.; et al. Carbon residence time dominates uncertainty in terrestrial vegetation responses to future climate and atmospheric $\mathrm{CO}_{2}$. Proc. Natl. Acad. Sci. USA 2014, 111, 3280-3285. [CrossRef]

22. Manusch, C.; Bugmann, H.; Heiri, C.; Wolf, A. Tree mortality in dynamic vegetation models-A key feature for accurately simulating forest properties. Ecol. Model. 2012, 243, 101-111. [CrossRef]

23. Chander, G.; Haque, M.O.; Micijevic, E.; Barsi, J.A. A procedure for radiometric recalibration of landsat 5 tm reflective-band data. IEEE Trans. Geosci. Remote Sens. 2010, 48, 556-574. [CrossRef]

24. Keles, S. Optimum cutting ages in hybrid poplar plantations including carbon sequestration: A case study in turkey. Serie Ciencias Forestales Ambiente 2016, 22, 339-349. [CrossRef]

25. Badreldin, N.; Sanchez-Azofeifa, A. Estimating forest biomass dynamics by integrating multi-temporal landsat satellite images with ground and airborne lidar data in the coal valley mine, alberta, canada. Remote Sens. 2015, 7, 2832-2849. [CrossRef]

26. Ma, A.; Liu, B. Estimation of Forest Above-Ground Biomass Using Spot-5 Image in Mountain Areas; DEStech Publications: Lancaster, PA, USA, 2015.

27. Motlagh, M.G.; Kafaky, S.B.; Mataji, A.; Akhavan, R. Estimating and mapping forest biomass using regression models and spot-6 images (case study: Hyrcanian forests of north of iran). Environ. Monit. Assess. 2018, 190, 352. [CrossRef] [PubMed]

28. Muhd-Ekhzarizal, M.E.; Mohd-Hasmadi, I.; Hamdan, O.; Mohamad-Roslan, M.K.; Noor-Shaila, S. Estimation of aboveground biomass in mangrove forests using vegetation indices from spot-5 image. J. Trop. For. Sci. 2018, 30, $224-233$.

29. Ploton, P.; Barbier, N.; Couteron, P.; Antin, C.M.; Ayyappan, N.; Balachandran, N.; Barathan, N.; Bastin, J.F.; Chuyong, G.; Dauby, G.; et al. Toward a general tropical forest biomass prediction model from very high resolution optical satellite images. Remote Sens. Environ. 2017, 200, 140-153. [CrossRef]

30. Tao, S.; Guo, Q.; Wu, F.; Li, L.; Wang, S.; Tang, Z.; Xue, B.; Liu, J.; Fang, J. Spatial scale and pattern dependences of aboveground biomass estimation from satellite images: A case study of the sierra national forest, california. Landsc. Ecol. 2016, 31, 1711-1723. [CrossRef] 
31. Zhang, L.; Shao, Z.; Wang, Z. Estimation of forest aboveground biomass using the integration of spectral and textural features from gf-1 satellite image. In Proceedings of the 2016 4th International Workshop on Earth Observation and Remote Sensing Applications, Guangzhou, China, 4-6 July 2016.

32. Wang, K.; Franklin, S.E.; Guo, X.; Cattet, M. Remote sensing of ecology, biodiversity and conservation: A review from the perspective of remote sensing specialists. Sensors 2010, 10, 9647-9667. [CrossRef]

33. Wang, Z.; Liu, L.; Peng, D.; Liu, X.; Zhang, S.; Wang, Y. Estimating woody aboveground biomass in an area of agroforestry using airborne light detection and ranging and compact airborne spectrographic imager hyperspectral data: Individual tree analysis incorporating tree species information. J. Appl. Remote Sens. 2016, 10, 036007. [CrossRef]

34. Goldbergs, G.; Levick, S.R.; Lawes, M.; Edwards, A. Hierarchical integration of individual tree and area-based approaches for savanna biomass uncertainty estimation from airborne lidar. Remote Sens. Environ. 2018, 205, 141-150. [CrossRef]

35. Ledo, A.; Cornulier, T.; Illian, J.B.; Iida, Y.; Kassim, A.R.; Burslem, D.F.R.P. Re-evaluation of individual diameter:Height allometric models to improve biomass estimation of tropical trees. Ecol. Appl. 2016, 26, 2374-2380. [CrossRef]

36. Zeng, W.; Zhang, L.; Chen, X.; Cheng, Z.; Ma, K.; Li, Z. Construction of compatible and additive individual-tree biomass models for pinus tabulaeformis in china. Can. J. For. Res. 2017, 47, 467-475. [CrossRef]

37. Hosoda, K.; Iehara, T. Aboveground biomass equations for individual trees of cryptomeria japonica, chamaecyparis obtusa and larix kaempferi in japan. J. For. Res. 2010, 15, 299-306. [CrossRef]

38. Sanquetta, C.R.; Dalla Corte, A.P.; Behling, A.; de Oliveira Piva, L.R.; Netto, S.P.; Rodrigues, A.L.; Inoue Sanquetta, M.N. Selection criteria for linear regression models to estimate individual tree biomasses in the atlantic rain forest, Brazil. Carbon Balance Manag. 2018, 13, 25. [CrossRef] [PubMed]

39. Ter-Mikaelian, M.T.; Korzukhin, M.D. Biomass equations for sixty-five north american tree species. For. Ecol. Manag. 1997, 97, 1-24. [CrossRef]

40. Dong, L.; Zhang, L.; Li, F. Allometry and partitioning of individual tree biomass and carbon of abies nephrolepis maxim in northeast china. Scand. J. For. Res. 2016, 31, 399-411. [CrossRef]

41. Tahvanainen, T.; Forss, E. Individual tree models for the crown biomass distribution of scots pine, norway spruce and birch in Finland. For. Ecol. Manag. 2008, 255, 455-467. [CrossRef]

42. Zeng, W.-S. Using nonlinear mixed model and dummy variable model approaches to develop origin-based individual tree biomass equations. Trees-Struct. Funct. 2015, 29, 275-283. [CrossRef]

43. Fu, L.; Zeng, W.; Tang, S. Individual tree biomass models to estimate forest biomass for large spatial regions developed using four pine species in china. For. Sci. 2017, 63, 241-249.

44. Durkaya, B.; Durkaya, A.; Makineci, E.; Karaburk, T. Estimate above-ground biomass and carbon stock of individual trees in uneven-aged uludag fir stand. Fresenius Environ. Bull. 2013, 22, 428-434.

45. Haara, A.; Nevalainen, S. Detection of dead or defoliated spruces using digital aerial data. For. Ecol Manag 2002, 160, 97-107. [CrossRef]

46. Trotsiuk, V.; Svoboda, M.; Weber, P.; Pederson, N.; Klesse, S.; Janda, P.; Martin-Benito, D.; Mikolas, M.; Seedre, M.; Bace, R.; et al. The legacy of disturbance on individual tree and stand-level aboveground biomass accumulation and stocks in primary mountain picea abies forests. For. Ecol. Manag. 2016, 373, 108-115. [CrossRef]

47. Popescu, S.C. Estimating biomass of individual pine trees using airborne lidar. Biomass Bioenergy 2007, 31, 646-655. [CrossRef]

48. Wulder, M.A.; White, J.C.; Nelson, R.F.; Naesset, E.; Orka, H.O.; Coops, N.C.; Hilker, T.; Bater, C.W.; Gobakken, T. Lidar sampling for large-area forest characterization: A review. Remote Sens. Environ. 2012, 121, 196-209. [CrossRef]

49. Riggio, M.; Anthony, R.W.; Augelli, F.; Kasal, B.; Lechner, T.; Muller, W.; Tannert, T. In situ assessment of structural timber using non-destructive techniques. Mater. Struct. 2014, 47, 749-766. [CrossRef]

50. Cao, L.; Gao, S.; Li, P.; Yun, T.; Shen, X.; Ruan, H. Aboveground biomass estimation of individual trees in a coastal planted forest using full-waveform airborne laser scanning data. Remote Sens. 2016, 8, 729. [CrossRef]

51. Giannico, V.; Lafortezza, R.; John, R.; Sanesi, G.; Pesola, L.; Chen, J. Estimating stand volume and above-ground biomass of urban forests using lidar. Remote Sens. 2016, 8, 339. [CrossRef]

52. Popescu, S.C.; Wynne, R.H.; Nelson, R.F. Measuring individual tree crown diameter with lidar and assessing its influence on estimating forest volume and biomass. Can. J. Remote Sens. 2003, 29, 564-577. [CrossRef]

53. Beland, M.; Parker, G.; Sparrow, B.; Harding, D.; Chasmer, L.; Phinn, S.; Antonarakis, A.; Strahler, A. On promoting the use of lidar systems in forest ecosystem research. For. Ecol. Manag. 2019, 450, 117484. [CrossRef]

54. Wang, D.; Takoudjou, S.M.; Casella, E. Lewos: A universal leaf-wood classification method to facilitate the 3D modelling of large tropical trees using terrestrial lidar. Methods Ecol. Evol. 2020, 11, 376-389. [CrossRef]

55. Calders, K.; Armston, J.; Newnham, G.; Herold, M.; Goodwin, N. Implications of sensor configuration and topography on vertical plant profiles derived from terrestrial lidar. Agric. For. Meteorol. 2014, 194, 104-117. [CrossRef]

56. Takoudjou, S.M.; Ploton, P.; Sonke, B.; Hackenberg, J.; Griffon, S.; de Coligny, F.; Kamdem, N.G.; Libalah, M.; Mofack, G.I.; Le Moguedec, G.; et al. Using terrestrial laser scanning data to estimate large tropical trees biomass and calibrate allometric models: A comparison with traditional destructive approach. Methods Ecol. Evol. 2018, 9, 905-916. [CrossRef]

57. Stovall, A.E.L.; Vorster, A.G.; Anderson, R.S.; Evangelista, P.H.; Shugart, H.H. Non-destructive aboveground biomass estimation of coniferous trees using terrestrial lidar. Remote Sens. Environ. 2017, 200, 31-42. [CrossRef] 
58. Brede, B.; Calders, K.; Lau, A.; Raumonen, P.; Bartholomeus, H.M.; Herold, M.; Kooistra, L. Non-destructive tree volume estimation through quantitative structure modelling: Comparing uav laser scanning with terrestrial lidar. Remote Sens. Environ. 2019, 233, 111355. [CrossRef]

59. Wang, X.; Xie, D.; Yan, G.; Zhang, W.; Wang, Y.; Chen, Y. 3D reconstruction of a single tree from terrestrial lidar data. In Proceedings of the 2014 IEEE International Geoscience and Remote Sensing Symposium, Québec City, QC, Canada, 13-18 July 2014; pp. 796-799.

60. Ehbrecht, M.; Schall, P.; Juchheim, J.; Ammer, C.; Seidel, D. Effective number of layers: A new measure for quantifying three-dimensional stand structure based on sampling with terrestrial lidar. For. Ecol. Manag. 2016, 380, 212-223. [CrossRef]

61. Kim, A.M.; Olsen, R.C.; Beland, M. Simulated full-waveform lidar compared to riegl vz-400 terrestrial laser scans. In Laser Radar Technology and Applications XXI; Turner, M.D., Kamerman, G.W., Eds.; SPIE: Bellingham, WA, USA, 2016; Volume 9832.

62. Yang, X.; Strahler, A.H.; Schaaf, C.B.; Jupp, D.L.B.; Yao, T.; Zhao, F.; Wang, Z.; Culvenor, D.S.; Newnham, G.J.; Lovell, J.L.; et al. Three-dimensional forest reconstruction and structural parameter retrievals using a terrestrial full-waveform lidar instrument (echidn (r)). Remote Sens. Environ. 2013, 135, 36-51. [CrossRef]

63. Bremer, M.; Wichmann, V.; Rutzinger, M. Multi-temporal fine-scale modelling of larix decidua forest plots using terrestrial lidar and hemispherical photographs. Remote Sens. Environ. 2018, 206, 189-204. [CrossRef]

64. Hildebrandt, R.; Iost, A. From points to numbers: A database-driven approach to convert terrestrial lidar point clouds to tree volumes. Eur. J. For. Res. 2012, 131, 1857-1867. [CrossRef]

65. Bazezew, M.N.; Hussin, Y.A.; Kloosterman, E.H. Integrating airborne lidar and terrestrial laser scanner forest parameters for accurate above-ground biomass/carbon estimation in ayer hitam tropical forest, malaysia. Int. J. Appl. Earth Obs. Geoinf. 2018, 73, 638-652. [CrossRef]

66. Xie, D.; Wang, X.; Qi, J.; Chen, Y.; Mu, X.; Zhang, W.; Yan, G. Reconstruction of single tree with leaves based on terrestrial lidar point cloud data. Remote Sens. 2018, 10, 686. [CrossRef]

67. Huang, H.; Tang, L.; Chen, C. A 3d Individual Tree Modeling Technique Based on Terrestrial Lidar Point Cloud Data. In Proceedings of the 2015 2nd IEEE International Conference on Spatial Data Mining and Geographical Knowledge Services, Fuzhou, China, 8-10 July 2015; pp. 152-156.

68. Tao, S.; Wu, F.; Guo, Q.; Wang, Y.; Li, W.; Xue, B.; Hu, X.; Li, P.; Tian, D.; Li, C.; et al. Segmenting tree crowns from terrestrial and mobile lidar data by exploring ecological theories. ISPRS J. Photogramm. Remote Sens. 2015, 110, 66-76. [CrossRef]

69. Vicari, M.B.; Disney, M.; Wilkes, P.; Burt, A.; Calders, K.; Woodgate, W. Leaf and wood classification framework for terrestrial lidar point clouds. Methods Ecol. Evol. 2019, 10, 680-694. [CrossRef]

70. Bauwens, S.; Bartholomeus, H.; Calders, K.; Lejeune, P. Forest inventory with terrestrial lidar: A comparison of static and hand-held mobile laser scanning. Forests 2016, 7, 127. [CrossRef]

71. Kankare, V.; Raety, M.; Yu, X.; Holopainen, M.; Vastaranta, M.; Kantola, T.; Hyyppa, J.; Hyyppa, H.; Alho, P.; Viitala, R. Single tree biomass modelling using airborne laser scanning. ISPRS J. Photogramm. Remote Sens. 2013, 85, 66-73. [CrossRef]

72. Kankare, V.; Vauhkonen, J.; Holopainen, M.; Vastaranta, M.; Hyyppa, J.; Hyyppa, H.; Alho, P. Sparse density, leaf-off airborne laser scanning data in aboveground biomass component prediction. Forests 2015, 6, 1839-1857. [CrossRef]

73. White, J.C.; Coops, N.C.; Wulder, M.A.; Vastaranta, M.; Hilker, T.; Tompalski, P. Remote sensing technologies for enhancing forest inventories: A review. Can. J. Remote Sens. 2016, 42, 619-641. [CrossRef]

74. Kaartinen, H.; Hyyppa, J.; Yu, X.; Vastaranta, M.; Hyyppa, H.; Kukko, A.; Holopainen, M.; Heipke, C.; Hirschmugl, M.; Morsdorf, F.; et al. An international comparison of individual tree detection and extraction using airborne laser scanning. Remote Sens. 2012, 4, 950-974. [CrossRef]

75. Vauhkonen, J.; Korpela, I.; Maltamo, M.; Tokola, T. Imputation of single-tree attributes using airborne laser scanning-based height, intensity, and alpha shape metrics. Remote Sens. Environ. 2010, 114, 1263-1276. [CrossRef]

76. Usoltsev, V.A.; Shobairi, S.O.R.; Chasovskikh, V.P. Comparing of allometric models of single-tree biomass intended for airborne laser sensing and terrestrial taxation of carbon pool in the forests of eurasia. Nat. Resour. Model. 2019, 32, e12187. [CrossRef]

77. Fu, L.; Liu, Q.; Sun, H.; Wang, Q.; Li, Z.; Chen, E.; Pang, Y.; Song, X.; Wang, G. Development of a system of compatible individual tree diameter and aboveground biomass prediction models using error-in-variable regression and airborne lidar data. Remote Sens. 2018, 10, 325. [CrossRef]

78. Wan-Mohd-Jaafar, W.S.; Woodhouse, I.H.; Silva, C.A.; Omar, H.; Hudak, A.T. Modelling individual tree aboveground biomass using discrete return lidar in lowland dipterocarp forest of malaysia. J. Trop. For. Sci. 2017, 29, 465-484.

79. Apostol, B.; Lorent, A.; Petrila, M.; Gancz, V.; Badea, O. Height extraction and stand volume estimation based on fusion airborne lidar data and terrestrial measurements for a norway spruce Picea abies (L.) Karst. Test site in romania. Not. Bot. Hortic. Agrobot. Cluj-Napoca 2016, 44, 313-323. [CrossRef]

80. Dong, T.; Zhou, Q.; Gao, S.; Shen, Y. Automatic detection of single trees in airborne laser scanning data through gradient orientation clustering. Forests 2018, 9, 291. [CrossRef]

81. Zhang, J.; Sohn, G.; Bredif, M. A hybrid framework for single tree detection from airborne laser scanning data: A case study in temperate mature coniferous forests in ontario, canada. ISPRS J. Photogramm. Remote Sens. 2014, 98, 44-57. [CrossRef]

82. Ene, L.; Naesset, E.; Gobakken, T. Single tree detection in heterogeneous boreal forests using airborne laser scanning and area-based stem number estimates. Int. J. Remote Sens. 2012, 33, 5171-5193. [CrossRef] 
83. Heurich, M. Automatic recognition and measurement of single trees based on data from airborne laser scanning over the richly structured natural forests of the bavarian forest national park. For. Ecol. Manag. 2008, 255, 2416-2433. [CrossRef]

84. Vastaranta, M.; Saarinen, N.; Kankare, V.; Holopainen, M.; Kaartinen, H.; Hyyppa, J.; Hyyppa, H. Multisource single-tree inventory in the prediction of tree quality variables and logging recoveries. Remote Sens. 2014, 6, 3475-3491. [CrossRef]

85. Hauglin, M.; Dibdiakova, J.; Gobakken, T.; Naesset, E. Estimating single-tree branch biomass of norway spruce by airborne laser scanning. ISPRS J. Photogramm. Remote Sens. 2013, 79, 147-156. [CrossRef]

86. Hauglin, M.; Gobakken, T.; Astrup, R.; Ene, L.; Naesset, E. Estimating single-tree crown biomass of norway spruce by airborne laser scanning: A comparison of methods with and without the use of terrestrial laser scanning to obtain the ground reference data. Forests 2014, 5, 384-403. [CrossRef]

87. Murgoitio, J.; Shrestha, R.; Glenn, N.; Spaete, L. Airborne lidar and terrestrial laser scanning derived vegetation obstruction factors for visibility models. Trans. Gis 2014, 18, 147-160. [CrossRef]

88. Wu, X.; Shen, X.; Cao, L.; Wang, G.; Cao, F. Assessment of individual tree detection and canopy cover estimation using unmanned aerial vehicle based light detection and ranging (uav-lidar) data in planted forests. Remote Sens. 2019, 11, 908. [CrossRef]

89. Yan, W.; Guan, H.; Cao, L.; Yu, Y.; Gao, S.; Lu, J. An automated hierarchical approach for three-dimensional segmentation of single trees using uav lidar data. Remote Sens. 2018, 10, 1999. [CrossRef]

90. Wallace, L.; Lucieer, A.; Watson, C.S. Evaluating tree detection and segmentation routines on very high resolution uav lidar data. IEEE Trans. Geosci. Remote Sens. 2014, 52, 7619-7628. [CrossRef]

91. Balsi, M.; Esposito, S.; Fallavollita, P.; Nardinocchi, C. Single-tree detection in high-density lidar data from uav-based survey. Eur. J. Remote Sens. 2018, 51, 679-692. [CrossRef]

92. Dalla Corte, A.P.; Souza, D.V.; Rex, F.E.; Sanquetta, C.R.; Mohan, M.; Silva, C.A.; Zambrano, A.M.A.; Prata, G.; de Almeida, D.R.A.; Trautenmueller, J.W.; et al. Forest inventory with high-density uav-lidar: Machine learning approaches for predicting individual tree attributes. Comput. Electron. Agric. 2020, 179, 105815. [CrossRef]

93. Dalla Corte, A.P.; Rex, F.E.; Alves de Almeida, D.R.; Sanquetta, C.R.; Silva, C.A.; Moura, M.M.; Wilkinson, B.; Almeyda Zambrano, A.M.; da Cunha Neto, E.M.; Veras, H.F.P.; et al. Measuring individual tree diameter and height using gatoreye high-density uav-lidar in an integrated crop-livestock-forest system. Remote Sens. 2020, 12, 863. [CrossRef]

94. Chen, X.; Jiang, K.; Zhu, Y.; Wang, X.; Yun, T. Individual tree crown segmentation directly from uav-borne lidar data using the pointnet of deep learning. Forests 2021, 12, 131. [CrossRef]

95. Yin, D.; Wang, L. Individual mangrove tree measurement using uav-based lidar data: Possibilities and challenges. Remote Sens. Environ. 2019, 223, 34-49. [CrossRef]

96. Picos, J.; Bastos, G.; Miguez, D.; Alonso, L.; Armesto, J. Individual tree detection in a eucalyptus plantation using unmanned aerial vehicle (uav)-lidar. Remote Sens. 2020, 12, 885. [CrossRef]

97. Brede, B.; Lau, A.; Bartholomeus, H.M.; Kooistra, L. Comparing riegl ricopter uav lidar derived canopy height and dbh with terrestrial lidar. Sensors 2017, 17, 2371. [CrossRef]

98. Lu, J.; Wang, H.; Qin, S.; Cao, L.; Pu, R.; Li, G.; Sun, J. Estimation of aboveground biomass of robinia pseudoacacia forest in the yellow river delta based on uav and backpack lidar point clouds. Int. J. Appl. Earth Obs. Geoinf. 2020, 86, 102014. [CrossRef]

99. Yan, Z.; Liu, R.; Cheng, L.; Zhou, X.; Ruan, X.; Xiao, Y. A concave hull methodology for calculating the crown volume of individual trees based on vehicle-borne lidar data. Remote Sens. 2019, 11, 623. [CrossRef]

100. Xie, Y.; Zhang, J.; Chen, X.; Pang, S.; Zeng, H.; Shen, Z. Accuracy assessment and error analysis for diameter at breast height measurement of trees obtained using a novel backpack lidar system. For. Ecosyst. 2020, 7, 33. [CrossRef]

101. Zhang, C.; Yang, G.; Jiang, Y.; Xu, B.; Li, X.; Zhu, Y.; Lei, L.; Chen, R.; Dong, Z.; Yang, H. Apple tree branch information extraction from terrestrial laser scanning and backpack-lidar. Remote Sens. 2020, 12, 3592. [CrossRef]

102. Gregoire, T.G.; Næsset, E.; Mcroberts, R.E.; Ståhl, G.; Andersen, H.E.; Gobakken, T.; Ene, L.; Nelson, R. Statistical rigor in lidar-assisted estimation of aboveground forest biomass. Remote Sens Env. 2016, 173, 98-108. [CrossRef]

103. Yu, X.; Hyyppa, J.; Vastaranta, M.; Holopainen, M.; Viitala, R. Predicting individual tree attributes from airborne laser point clouds based on the random forests technique. ISPRS J. Photogramm. Remote Sens. 2011, 66, 28-37. [CrossRef]

104. Vauhkonen, J.; Ene, L.; Gupta, S.; Heinzel, J.; Holmgren, J.; Pitkänen, J.; Solberg, S.; Wang, Y.; Weinacker, H.; Hauglin, K.M. Comparative testing of single-tree detection algorithms under different types of forest. Forestry 2011, 85, 27-40. [CrossRef]

105. Liu, F.; Tan, C.; Lei, P.-F. Estimating individual tree aboveground biomass of the mid-subtropical forest using airborne lidar technology. J. Appl. Ecol. 2014, 25, 3229-3236.

106. Clark, M.L.; Roberts, D.A.; Ewel, J.J.; Clark, D.B. Estimation of tropical rain forest aboveground biomass with small-footprint lidar and hyperspectral sensors. Remote Sens. Environ. 2011, 115, 2931-2942. [CrossRef]

107. Estornell, J.; Ruiz, L.A.; Velazquez-Marti, B.; Hermosilla, T. Estimation of biomass and volume of shrub vegetation using lidar and spectral data in a mediterranean environment. Biomass Bioenergy 2012, 46, 710-721. [CrossRef]

108. Latifi, H.; Fassnacht, F.; Koch, B. Forest structure modeling with combined airborne hyperspectral and lidar data. Remote Sens. Environ. 2012, 121, 10-25. [CrossRef]

109. Dalponte, M.; Frizzera, L.; Orka, H.O.; Gobakken, T.; Naesset, E.; Gianelle, D. Predicting stem diameters and aboveground biomass of individual trees using remote sensing data. Ecol. Indic. 2018, 85, 367-376. [CrossRef] 
110. Ediriweera, S.; Pathirana, S.; Danaher, T.; Nichols, D. Estimating above-ground biomass by fusion of lidar and multispectral data in subtropical woody plant communities in topographically complex terrain in north-eastern australia. J. For. Res. 2014, 25, 761-771. [CrossRef]

111. Lucas, R.M.; Lee, A.C.; Bunting, P.J. Retrieving forest biomass through integration of casi and lidar data. Int. J. Remote Sens. 2018, 29, 1553-1577. [CrossRef]

112. Moe, K.T.; Owari, T.; Furuya, N.; Hiroshima, T. Comparing individual tree height information derived from field surveys, lidar and uav-dap for high-value timber species in northern japan. Forests 2020, 11, 223. [CrossRef]

113. Patrick, A.; Li, C. High throughput phenotyping of blueberry bush morphological traits using unmanned aerial systems. Remote Sens. 2017, 9, 1250. [CrossRef]

114. Giannetti, F.; Puletti, N.; Quatrini, V.; Travaglini, D.; Bottalico, F.; Corona, P.; Chirici, G. Integrating terrestrial and airborne laser scanning for the assessment of single-tree attributes in mediterranean forest stands. Eur. J. Remote Sens. 2018, 51, 795-807. [CrossRef]

115. Polewski, P.; Yao, W.; Cao, L.; Gao, S. Marker-free coregistration of uav and backpack lidar point clouds in forested areas. ISPRS J. Photogramm. Remote Sens. 2019, 147, 307-318. [CrossRef] 